\title{
Short fluorodeoxyuridine exposure of different human glioblastoma lines induces high-level accumulation of S-phase cells that avidly incorporate ${ }^{125}$ I-iododeoxyuridine
}

\author{
Florence Perillo-Adamer ${ }^{1}$, Angelika Bischof Delaloye ${ }^{1}$, Céline S. Genton², Andreas O. Schaffland ${ }^{1}$, Yves M. Dupertuis ${ }^{3}$, \\ Franz Buchegger ${ }^{1,4}$ \\ 1 Service of Nuclear Medicine, University Hospital of Lausanne, Rue du Bugnon 46, CH-1011 Lausanne, Switzerland \\ 2 Department of Biochemistry, University of Lausanne, Epalinges, Switzerland \\ ${ }^{3}$ Service of Nutrition, University Hospital of Geneva, Geneva, Switzerland \\ ${ }^{4}$ Service of Nuclear Medicine, University Hospital of Geneva, Geneva, Switzerland
}

Received: 6 June 2005 / Accepted: 15 September 2005 / Published online: 1 February 2006

(C) Springer-Verlag 2006

\begin{abstract}
Purpose: Radio-iododeoxyuridine (IdUrd) is a potential Auger radiation therapy agent incorporated into DNA during the synthesis phase. In this study we sought to optimise S-phase targeting by modulating cellular cycling and radio-IdUrd DNA incorporation using short non-toxic fluorodeoxyuridine (FdUrd) incubations.

Methods: Three human glioblastoma cell lines with different $p 53$ expression were pre-treated with various FdUrd conditions. After different intervals, ${ }^{125} \mathrm{I}$-IdUrd DNA incorporation was measured. Fluorescence-activated cell sorter cell cycle analysis was performed after identical intervals post FdUrd pre-treatment.

Results: The highest increase in ${ }^{125} \mathrm{I}$-IdUrd DNA incorporation was induced by 1 -h incubation with $1 \mu M$ FdUrd. Increase in radio-IdUrd DNA incorporation was greatest 16-24 h after FdUrd, reaching factors of $\geq 7.5$ over baseline incorporation in the three cell lines. Furthermore, cell synchronisation in $\mathrm{S}$ phase was observed with a peak of $\geq 69.5 \%$ in the three cell lines at 16 and $24 \mathrm{~h}$ post FdUrd, corresponding to an increase of 2.5-4.1 over baseline.

Conclusion: FdUrd-induced thymidine synthesis inhibition led to S-phase accumulation that was maximal after an interval of 16-24 $\mathrm{h}$ and time-correlated with the highest radio-IdUrd DNA incorporation. These observations might allow the rational design of an Auger radiation therapy targeting a maximal number of S-phase cells in single treatment cycles.
\end{abstract}

Florence Perillo-Adamer ( $\bullet$ )

Service of Nuclear Medicine,

University Hospital of Lausanne,

Rue du Bugnon 46,

CH-1011 Lausanne, Switzerland

e-mail: Florence.Adamer@chuv.ch

Tel.: +41-21-3144337, Fax: +41-21-3144349
Keywords: Iododeoxyuridine - Fluorodeoxyuridine S phase - Glioblastoma - Auger radiation

Eur J Nucl Med Mol Imaging (2006) 33:613-620

DOI 10.1007/s00259-005-0009-y

\section{Introduction}

Iododeoxyuridine (IdUrd), a thymidine (dThd) analogue, labelled with ${ }^{123} \mathrm{I}$ or ${ }^{125} \mathrm{I}$, is an interesting Auger radiation therapy agent [1]. However, two major limitations restrict its DNA incorporation and therapeutic efficacy: firstly, radio-IdUrd DNA incorporation is low because of competition from the endogenous nucleotide pool and a short biological half-life attributable to rapid in vivo catabolism and dehalogenation $[2,3]$, and secondly, therapeutic IdUrd targeting is restricted to cells in the synthesis phase ( $\mathrm{S}$ phase) of the cell cycle. Thus, for the short period of its in vivo availability, only cells in S phase can be efficiently targeted with radio-IdUrd.

In order to favour DNA incorporation of IdUrd, different groups, including ours, have studied inhibition of the de novo synthesis of dThd with agents such as fluorodeoxyuridine (FdUrd) [4-6], 5-fluorouracil [7] or methotrexate [7]. FdUrd, a dThd analogue, inhibits thymidylate synthase (TS) and depletes the TTP pool by acting as non-convertible substrate [8]. The depletion of the cellular TTP pool favours incorporation into DNA of exogenous dThd and dThd analogues such as IdUrd [4-7]. FdUrd has been shown to have an extended effect on TS inhibition even after its removal in the human colon carcinoma cell line HT 29 [9]. Clinically, push administration of FdUrd, used in the early 1960s, is also well tolerated at high doses [10]. However, prolonged exposure to low doses of FdUrd leads to clonogenic death of HT29 
cells [11]. Our recent studies $[6,12]$ have shown that short i.v. treatment of animals with FdUrd allows a significant improvement in tumour DNA incorporation of radioIdUrd. However, while different groups have shown that FdUrd pre- or co-treatment results in the expected increase in incorporation of radio-IdUrd into DNA [4-7], a corresponding improvement in the efficacy of treatment has not been observed [4].

Due to the absence of improved efficacy of the different Auger radiation therapy approaches with radio-IdUrd (also evident in personal unpublished observations), we advanced the hypothesis that the limitation of S-phase targeting has not been addressed adequately. In fact, our previous observation of increased radio-IdUrd DNA incorporation immediately post FdUrd treatment $[6,12]$ still targeted only the very limited number of cells in $\mathrm{S}$ phase at radio-IdUrd incubation in vitro or injection in vivo. Therefore, in this study we investigated whether S-phase accumulation might be achieved in different glioblastoma cell lines. If S-phase accumulation and simultaneous high efficacy of radio-IdUrd DNA incorporation could be obtained, we would expect these combined effects to allow the design of a more rational Auger radiation therapy approach.

\section{Materials and methods}

\section{Reagents}

${ }^{125}$ I-IdUrd of high radiochemical purity was prepared from the precursor 5-tri- $n$-butyl-stannyl-2'-deoxyuridine and purified by SepPak RP-18 cartridges using a modified method [13] described originally by Foulon et al. [14]. Radiochemical purity was repeatedly verified with thin-layer chromatography using polyethyleneimine cellulose F strips (Merck, Darmstadt, Germany) with a mobile phase of $0.2 \mathrm{M}$ ammonium bicarbonate and radioactivity reading on a Tracemaster 20 (Berthold, Bad Wildbad, Germany). In all experiments, ${ }^{125}$ I-IdUrd represented $>98 \%$ of overall ${ }^{125}$ I activity. In the production of ${ }^{125}$ I-IdUrd, we were able to avoid contamination with unlabelled IdUrd [13]. It was calculated that the standard activity of $5 \mathrm{kBq}{ }^{125}$ I-IdUrd in $0.5 \mathrm{ml}$ used in the incorporation experiments represented a concentration of $0.2 \mathrm{n} M$, though this is only an indicative value as it has not been experimentally verified. FdUrd and dThd were obtained from Sigma-Aldrich Chemie GmbH (Steinheim, Germany). Stock solutions were prepared in distilled water at a concentration of $5 \mathrm{mM}$ and stored at $-80^{\circ} \mathrm{C}$. Unlabelled IdUrd (Sigma-Aldrich Chemie $\mathrm{GmbH}$ ) was dissolved in physiological $\mathrm{NaCl}$ using $\mathrm{NaOH}$ at minimally required concentration and stock solution $(50 \mathrm{mM})$ stored at $-80^{\circ} \mathrm{C}$

\section{Cell lines and culture}

Three human glioblastoma cell lines were chosen for their different p53 expression [15] that could potentially provide them with different repair capacities or FdUrd resistance [16]: U251 and U87 (American Type Culture Collection, ATCC) homozygous mutant and homozygous wild type, respectively, and the heterozygous line LN229 (gift from Prof. N. de Tribolet, Service of Neurosurgery, University Hospital, Geneva, Switzerland). Cells were cultured at $37^{\circ} \mathrm{C}$ and $5 \% \mathrm{CO}_{2}$ in RPMI 1640 with glutamax I, supplemented with $10 \%$ heat-inactivated fetal bovine serum (Chemie Brunschwig AG, Basel, Switzerland), penicillin (50 units/ml) and streptomycin $(0.05 \mathrm{mg} / \mathrm{ml}$; Life Technologies Inc., Grand Island, NY, USA), which was changed twice a week. Cell doubling times in culture flasks as measured by daily counting over 1 week were $24.6 \pm 2.3 \mathrm{~h}, 33.7 \pm 3.4 \mathrm{~h}$ and $34.0 \pm 0.2 \mathrm{~h}$ for $\mathrm{U} 251, \mathrm{LN} 229$ and U87, respectively $(n \geq 3)$. Because mycoplasma contamination is a potential source of increased nucleoside turnover $[17,18]$ and could therefore modulate FdUrd efficacy, all cells were tested negative for four major potential mycoplasma contaminations (Mycoplasma Detection Kit, F. Hoffmann-La Roche Ltd, Basel, Switzerland), and maximal cell culture time after testing was 6 months.

\section{${ }^{125}$ I-IdUrd incorporation assay}

To assess the effect of FdUrd on ${ }^{125}$ I-IdUrd incorporation into DNA, 24-well culture dishes were plated with 20,000 cells for LN229 and U87, and with 15,000 cells for U251. After 4 days, the exponentially growing cells were pre-treated for varying times and with varying doses of FdUrd, and washed twice with PBS $(\mathrm{NaCl} 0.15 \mathrm{M}$, phosphate $0.01 M, \mathrm{pH} 7.4$ ) before fresh medium was added. After different intervals of $0-72 \mathrm{~h}$, cells were incubated for $2 \mathrm{~h}$ at $37^{\circ} \mathrm{C}$ with $5 \mathrm{kBq}{ }^{125} \mathrm{I}$-IdUrd in $0.5 \mathrm{ml}$ medium. In a time course experiment with LN229 and U251 cells, we had observed that after incubation of cells for $2 \mathrm{~h}$, the large majority of intracellular radio-IdUrd was incorporated into DNA (results not shown). In accordance with published protocol $[4,19]$, cells were washed once with complete medium, twice with PBS and then recovered in 5-ml plastic tubes after incubation for $10 \mathrm{~min}$ with $200 \mu \mathrm{l}$ of trypsin-EDTA (Life Technologies Inc.). Wells were washed with $200 \mu$ l complete medium and this wash was also added to the cells. Thereafter, cells were lysed with $400 \mu \mathrm{l}$ of $1 \mathrm{M} \mathrm{NaOH}$. The DNA was precipitated with the addition of $400 \mu \mathrm{l}$ of $10 \%$ trichloroacetic acid (SigmaAldrich Chemie $\mathrm{GmbH}$ ) and the total volume of $1.2 \mathrm{ml}$ centrifuged for $30 \mathrm{~min}$ at $3,500 \mathrm{~g}$. A half volume was separated as one-half supernatant, and the remaining half volume $(0.6 \mathrm{ml})$ was considered as sediment (containing DNA) plus another half supernatant. Radioactivity was determined in a gamma counter (Wizard 3" 1480 automatic gamma counter, Wallac Oy, Turku, Finland) and results expressed for total cellular uptake (sediment + supernatant) of radio-IdUrd and for DNA-incorporated activity (sediment alone). All results given here represent DNA-incorporated radioactivity that was generally $>85 \%$ of cell-bound activity. In all timing experiments, cells were counted in identically treated control wells and DNAincorporated activity was normalised according to the number of cells.

\section{Fluorescence-activated cell sorter (FACS) analysis}

Cells were analysed by two-parameter flow cytometry measuring both DNA content by propidium iodide (PI) (Fluka Chemie AG, Buchs, Switzerland) and labelling index with IdUrd [6]. Exponentially growing cells were either pre-treated or not with $1 \mu M$ FdUrd for $1 \mathrm{~h}$, washed with PBS, incubated in fresh medium for $0-72 \mathrm{~h}$ and labelled with $10 \mu \mathrm{M}$ non-radioactive IdUrd for $1 \mathrm{~h}$. For LN229 and U251 cells, one of three experiments was performed with $3 \mu M$ IdUrd. Cells were then washed twice with PBS, trypsinised, centrifuged for $15 \mathrm{~min}$ at $500 \mathrm{~g}$, resuspended in PBS, diluted and fixed as aliquots of $10^{6}$ cells in $4 \mathrm{ml} 70 \%$ cold ethanol for $30 \mathrm{~min}$ on ice. Cells were centrifuged for $10 \mathrm{~min}$ at $500 \mathrm{~g}$ and $4^{\circ} \mathrm{C}$. The DNA was denatured by incubating the cells in $1 \mathrm{ml} 2 \mathrm{M} \mathrm{HCl} / 0.5 \% \mathrm{BSA} /$ PBS for $30 \mathrm{~min}$ at room temperature. Cells were centrifuged, and acid cell sediment was neutralised by resuspension in $1 \mathrm{ml}$ of $0.1 \mathrm{M}$ sodium borate at $\mathrm{pH} 8.5$. After centrifugation for $10 \mathrm{~min}$ at $500 \mathrm{~g}$, 
cells were either stored at $-20^{\circ} \mathrm{C}$ or directly prepared for FACS analysis by incubating them for $30 \mathrm{~min}$ at room temperature in $50 \mu \mathrm{l}$ $0.5 \%$ Tween $20 / 0.5 \%$ BSA/PBS containing $0.5 \mu \mathrm{g}$ of mouse monoclonal antibody against anti-BrdUrd (Dako A/S, Glostrup, Denmark) cross-reacting with IdUrd. After incubation, $1 \mathrm{ml}$ PBS was added before centrifugation $\left(10 \mathrm{~min}\right.$ at $500 \mathrm{~g}$ and $\left.4^{\circ} \mathrm{C}\right)$. Then, the pellet was resuspended in $50 \mu \mathrm{l}$ of $0.5 \%$ Tween $20 / 0.5 \%$ BSA/PBS with $1 \mu \mathrm{g}$ of anti-mouse IgG conjugated with FITC (Sigma-Aldrich Chemie $\mathrm{GmbH}$ ) and incubated for another $30 \mathrm{~min}$ at room temperature. Cells were washed with $1 \mathrm{ml}$ PBS, centrifuged and resuspended in $1 \mathrm{ml}$ of PBS containing $2.5 \mu \mathrm{g} / \mathrm{ml}$ PI. Samples were incubated for $16-20 \mathrm{~h}$ at $4{ }^{\circ} \mathrm{C}$ before analysis on a flow cytometer (FACScan; Becton Dickinson, Franklin Lakes, NJ, USA) with a laser excitation at $488 \mathrm{~nm}$ for PI and FITC fluorescence.

\section{External beam irradiation and cell survival assay}

Twenty-four well culture dishes were plated with 20,000 and 15,000 cells for LN229 and U251, respectively, 4 days prior to treatment. After pre-treatment for $1 \mathrm{~h}$ with $1 \mu M \mathrm{FdUrd}$, cells were washed, reincubated with fresh medium and irradiated at the times indicated in a photon beam (6 MeV Primus Linear Accelerator, Siemens AG, Munich, Germany) at doses of 2 or 6 Gy. The colony-forming assay was then used to measure the cell survival fraction: cells were trypsinised, resuspended in RPMI 1640 and counted. The cell suspension was serially diluted and 200 or 2,000 viable cells were plated into $100 \times 20 \mathrm{~mm}$ tissue culture dishes in $10 \mathrm{ml}$ fresh culture medium. After 14 days of incubation at $37^{\circ} \mathrm{C}$ and $5 \% \mathrm{CO}_{2}$, grown colonies were fixed and stained with $0.5 \%$ crystal violet in methanol/ acetic acid $(3: 1, \mathrm{v} / \mathrm{v})$. Colonies containing $\geq 50$ cells were counted. Each experiment was performed using triplicates and repeated at least three times. The survival fraction $\left(\mathrm{S} / \mathrm{S}_{0}\right)$ was calculated as the plating efficiency of irradiated pre-treated cells divided by the plating efficiency of corresponding unirradiated pre-treated cells. The colony-forming assay cannot be performed in liquid medium with U87 cells because they form spheroids and can detach. For this reason, this line was not tested in this assay.

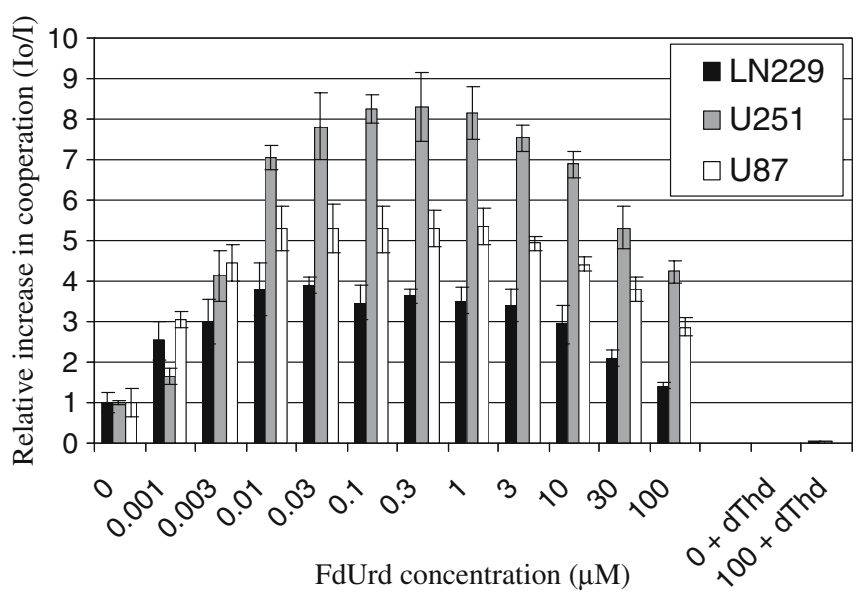

Fig. 1. Increase in DNA incorporation (I/Io) of ${ }^{125} \mathrm{I}$-IdUrd according to the concentration of FdUrd. Cells were co-incubated with $5 \mathrm{kBq}$

${ }^{125}$ I-IdUrd and with/without FdUrd $(0.001-100 \mu M)$. Results (mean \pm 1 SD) are from three independent experiments, each performed with three samples per test condition. Results are normalised to control samples incubated for $4 \mathrm{~h}$ with radio-IdUrd alone. Additional controls of incorporation were performed by competition with $50 \mu M$ thymidine (+dThd)

\section{Statistical analysis}

Statistical multi-group comparisons were performed with the ANOVA multiple range Tukey-HSD test at different confidence levels using the UNISTAT 5.5 statistical package for Windows (2002 edition, Unistat Ltd, London, UK, run on Windows XP). The TukeyHSD test applies the largest range value independent of the effective subset size; it is more conservative than the Student-Newman-Keuls test but less conservative than the Scheffé or the Bonferroni test.

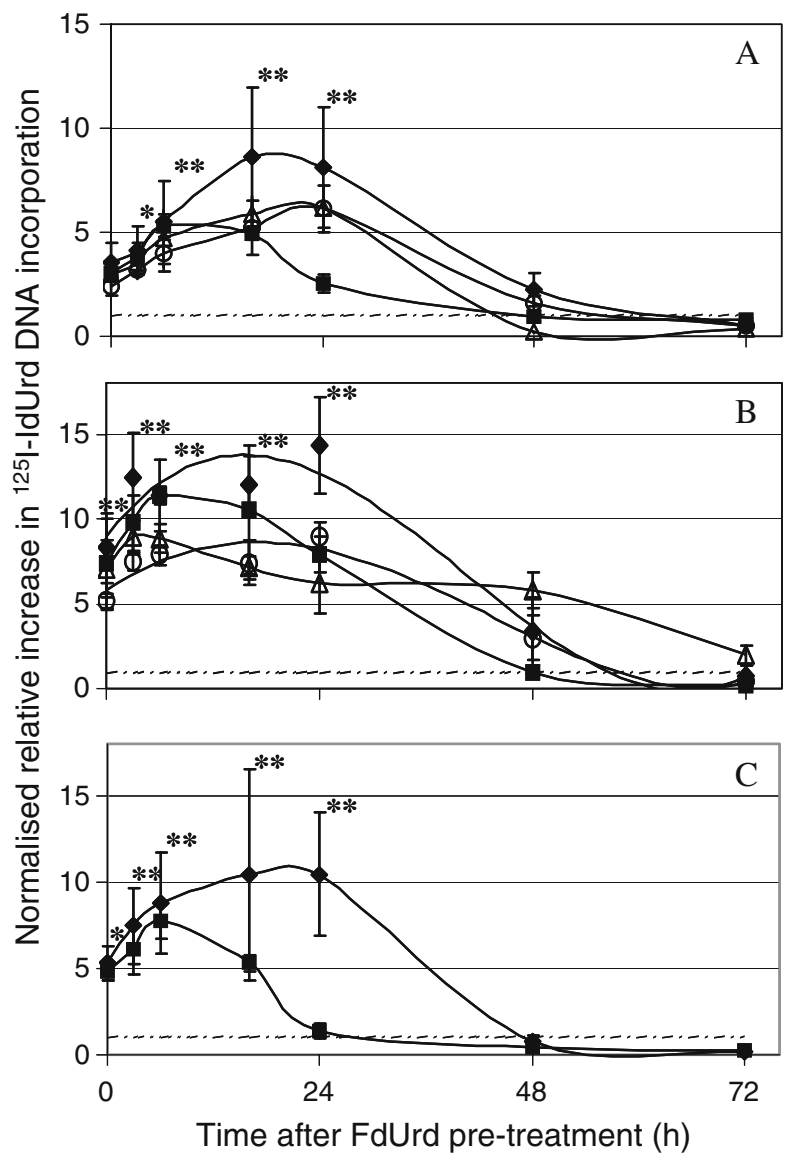

Fig. 2. Incorporation kinetics of ${ }^{125} \mathrm{I}$-IdUrd according to the interval after FdUrd pre-treatment, for LN229 (a), U251 (b) and U87 (c) cell lines. The different pre-treatments were: $1 \mu M$ FdUrd for $1 \mathrm{~h}(\downarrow)$, $10 \mu M$ FdUrd for $1 \mathrm{~h}(\Delta), 1 \mu M$ FdUrd for $10 \mathrm{~min}(\mathbf{a})$ and $10 \mu M$ FdUrd for $10 \mathrm{~min}(\circ)$. After various intervals post FdUrd pretreatment, cells were incubated for $2 \mathrm{~h}$ with $5 \mathrm{kBq}{ }^{125} \mathrm{I}$-IdUrd. The mean values $\pm 1 \mathrm{SD}$ of three independent experiments are shown, each performed with three to four measurements per condition. The results represent relative increase in DNA incorporation of radioIdUrd for pre-treated cells divided by untreated samples (I/Io) and normalised to the number of cells per well. Baseline relative DNA incorporation is represented by a broken line. ${ }^{*}$ and $* *$ denote results that were significantly $(p<0.05)$ or highly significantly $(p<0.001)$ different compared with untreated control cells 


\section{Results}

Dependence of ${ }^{125}$ I-IdUrd DNA incorporation on FdUrd concentration

First experiments were performed on the three glioblastoma cell lines in exponential growth using co-incubation for $4 \mathrm{~h}$ with $5 \mathrm{kBq}{ }^{125}$ I-IdUrd and different concentrations of FdUrd. Depending on the FdUrd concentration, increased DNA incorporation of radio-IdUrd up to a plateau was observed compared with untreated cells. A maximum increase in incorporation of 4.0- to 8.5 -fold was obtained in the three cell lines with FdUrd concentrations between 0.01 and $3 \mu M$ (Fig. 1). A high percentage incorporation of radio-IdUrd in absolute amount (results not shown) might have been partially responsible for the observed plateau. At concentrations of $10 \mu M$ FdUrd or higher, the DNA incorporation of radio-IdUrd decreased in all cells and coincubation with dThd almost completely abolished it (Fig. 1). Compared with previous experiments [6], the results presented here show a higher efficacy of FdUrd and a higher absolute amount of radio-IdUrd incorporated. This might be related to mycoplasma contamination in previous experiments, though this has not been formally demonstrated. The cells used here, however, were checked for the absence of mycoplasma contamination.

\section{Delayed effect of FdUrd pre-treatment on DNA incorporation of ${ }^{125}$ I-IdUrd}

Shorter incubation times of 10 and 60 min with 1 and $10 \mu M$ FdUrd were further evaluated because of the known low toxicity and efficacy of such treatments [6, 10]. Though some growth delay was observed with direct cell counting, absence of cytotoxicity of these treatments was confirmed in LN229 and U251 cells with the colonyforming assay (results not shown). Cells were pre-treated with FdUrd, washed to eliminate trace amounts of FdUrd that could influence the cell cycle and re-incubated with fresh medium for $0-72 \mathrm{~h}$, following which the radio-IdUrd incorporation rate was measured in a 2 -h incubation. Incubation with $1 \mu M$ FdUrd for $1 \mathrm{~h}$ was the pre-treatment which gave the highest increase in ${ }^{125}$ I-IdUrd DNA incorporation and the most prolonged effect for the three glioblastoma cell lines (Fig. 2). Under this condition, the incorporation rate increased to a maximum after an interval of 16-24 h post FdUrd pre-treatment (all results are corrected for the number of counted cells). Incorporation increased by factors of 7.5, 10 and 12 or more for LN229, U87 and U251, respectively, compared with un-pretreated cells $(p>0.001)$. This corresponded, at $24 \mathrm{~h}$ post FdUrd, to $16.4 \%, 35.1 \%$ and $50.7 \%$ DNA incorporation in absolute amount calculated on the total radio-IdUrd present during the 2-h incubation for the LN229, U87 and U251, respectively (results not shown). The immediate increase in incorporation post FdUrd exposure (time 0, Fig. 2) was similar to that seen in the 4-h co-incubation experiments shown above, but it was significantly less $(p<0.05$ for the three cell lines) than at 16 and $24 \mathrm{~h}$ post FdUrd. The other pre-treatments also favoured ${ }^{125} \mathrm{I}$-IdUrd DNA incorporation, but the increase in incorporation was not as high as with $1 \mu M$ FdUrd for $1 \mathrm{~h}$. In particular, the shorter incubation period of 10 min was insufficient to produce a similar effect, despite the use of a higher concentration of FdUrd. Furthermore, the maximum increase in incorporation tended to occur earlier post FdUrd for the other pretreatments (Fig. 2).

\section{Cell cycle distribution according to the interval after FdUrd pre-treatment}

Cell cycle distribution was then assessed by double staining FACS analysis after the optimal pre-treatment for $1 \mathrm{~h}$ with $1 \mu M \mathrm{FdUrd}$. Highly reproducible results were observed in independent experiments performed with LN229, U251 and U87 cells. Incubation with $3 \mu M$ (one experiment performed on LN229 and U251 cells) or $10 \mu M$ IdUrd (two experiments on the three cell lines) gave identical results, which were pooled (Table 1). As controls, antibody anti-IdUrd staining was negative for cells

Table 1. Cell cycle FACS analysis

\begin{tabular}{llllllllll}
\hline Interval & & $0 \mathrm{~h}$ & $3 \mathrm{~h}$ & $6 \mathrm{~h}$ & $16 \mathrm{~h}$ & $24 \mathrm{~h}$ & $48 \mathrm{~h}$ & $72 \mathrm{~h}$ & Untreated controls \\
\hline LN229 & $\mathrm{G} 1$ & $62.9 \pm 1.4$ & $60.3 \pm 2.1$ & $56.1 \pm 3.0$ & $19.5 \pm 0.4^{* *}$ & $18.3 \pm 3.6^{* *}$ & $43.8 \pm 8.0^{* *}$ & $68.4 \pm 2.9$ & $64.2 \pm 1.3$ \\
& $\mathrm{~S}$ & $30.3 \pm 1.1$ & $34.0 \pm 3.0$ & $39.5 \pm 1.9\left[^{*}\right]$ & $75.7 \pm 1.3^{* *}$ & $71.4 \pm 4.6^{* *}$ & $47.3 \pm 7.6^{*}$ & $23.7 \pm 2.1$ & $28.7 \pm 1.4$ \\
& $\mathrm{G} 2$ & $5.4 \pm 0.1$ & $3.9 \pm 0.7$ & $1.8 \pm 0.3^{*}$ & $2.7 \pm 0.3^{*}$ & $\left.9.0 \pm 2.2^{*}\right]$ & $6.8 \pm 0.9$ & $6.2 \pm 0.5$ & $6.2 \pm 0.6$ \\
U251 & $\mathrm{G} 1$ & $55.8 \pm 1.9$ & $56.8 \pm 2.6$ & $54.8 \pm 3.5$ & $25.2 \pm 1.7^{* *}$ & $18.7 \pm 1.2^{* *}$ & $52.8 \pm 12.1$ & $77.8 \pm 0.6\left(^{*}\right)$ & $60.5 \pm 3.1$ \\
& $\mathrm{~S}$ & $27.9 \pm 2.4\left[^{*}\right]$ & $26.7 \pm 1.8$ & $34.0 \pm 4.1^{*}$ & $69.5 \pm 1.8^{* *}$ & $76.0 \pm 1.0^{* *}$ & $26.8 \pm 7.4$ & $6.4 \pm 0.5\left(^{*}\right)$ & $18.5 \pm 2.3$ \\
& $\mathrm{G} 2$ & $15.7 \pm 0.5^{*}$ & $16.2 \pm 1.5^{*}$ & $10.2 \pm 1.0^{* *}$ & $4.2 \pm 0.7^{* *}$ & $4.5 \pm 0.4^{* *}$ & $19.9 \pm 2.8$ & $15.5 \pm 0.1^{*}$ & $20.5 \pm 0.7$ \\
U87 & $\mathrm{S}$ & 29.3 & 32.7 & 38.8 & 82.5 & 79.3 & 32.6 & 22.9 & 25.5 \\
& & 25.3 & 32.0 & 30.8 & 73.4 & 82.4 & 26.4 & 25.9 & 26.9
\end{tabular}

Flow cytometry was performed at the indicated intervals post FdUrd pre-treatment ( $1 \mu M$ FdUrd for $1 \mathrm{~h})$. Mean values \pm 1 SD of three independent FACS analyses are given for LN229 and U251 cells. S-phase results of two FACS analyses are given for U87 cells.

$*$ and $* *$ denote results that were significantly $(p<0.05)$ or highly significantly $(p<0.001)$ different compared with untreated control cells. $(*)$ and [*] indicate differences that were close to significance, at $p<0.07$ and $p<0.15$, respectively 
Fig. 3. Cell cycle distribution in untreated controls and 16 and $24 \mathrm{~h}$ after pre-treatment with $1 \mu M$ FdUrd for $1 \mathrm{~h}$. Representative FACS results for LN229 $(\mathbf{a}-\mathbf{c})$ and $\mathrm{U} 251(\mathbf{d}-\mathbf{f})$ are shown. The incorporated IdUrd, revealed by FITC immunofluorescence, is plotted against DNA content of cells, revealed by PI staining. Note the accumulation in early $\mathrm{S}$ phase (and depletion of G2) in $\mathbf{b}, \mathbf{e}$ and f. LN229 cell block-release occurs at $24 \mathrm{~h}$ post FdUrd (c). Results of the complete cycle analysis at different intervals post FdUrd are given in Table 1
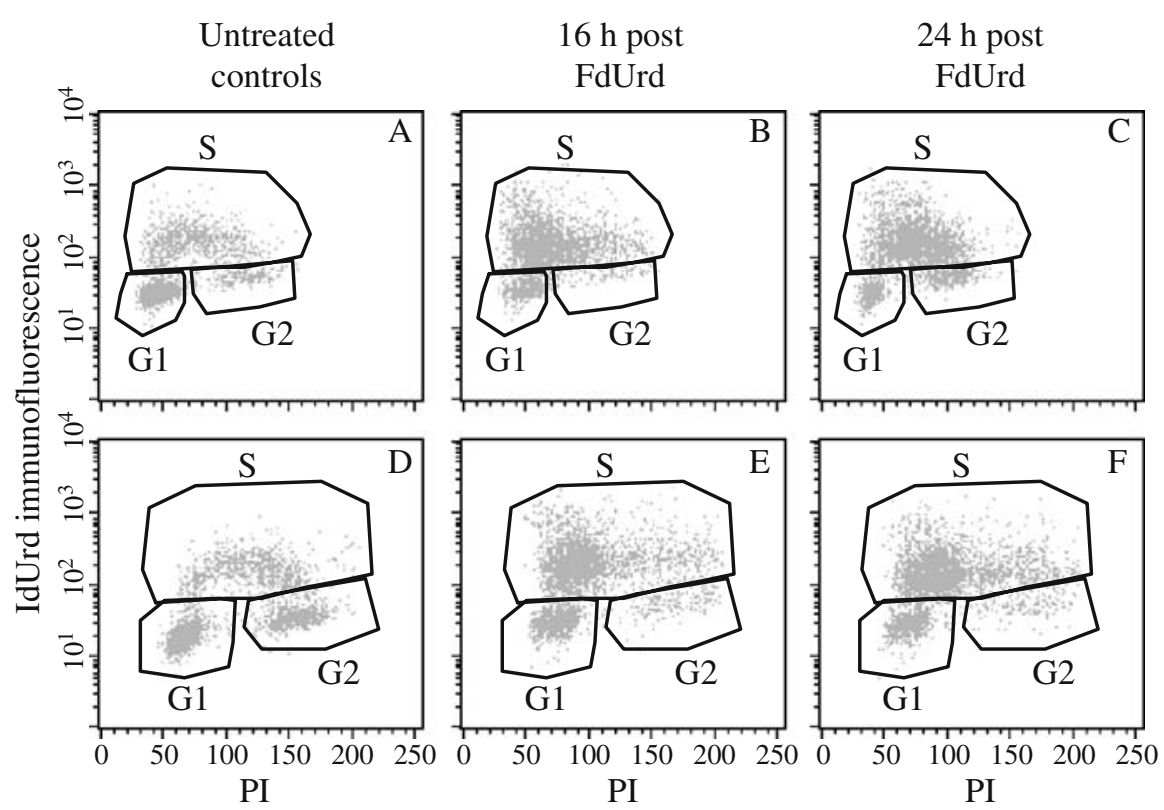

incubated with FdUrd alone, dThd inhibited IdUrd DNA incorporation and the absence of primary antibody also gave a negative result (data not shown).

As shown (Fig. 3 and Table 1), the rate of S-phase cells increased to $69.5 \%$ or higher at $16-24 \mathrm{~h}$ after FdUrd pretreatment, compared with baseline rates of $28.7 \%, 18.5 \%$ and $25.5 \%$ for un-pretreated LN229, U251 and U87 cells, respectively. The S-phase increase at 16 and $24 \mathrm{~h}$ was highly significant $(p<0.001)$ compared with both untreated cells and cells evaluated immediately after FdUrd pretreatment $(t=0)$. G1 and G2 phases decreased at these times to the benefit of the $\mathrm{S}$ phase. Interestingly, while the cell cycle distribution of LN229 and U87 cells had returned to about baseline $72 \mathrm{~h}$ after FdUrd removal (Table 1), results in respect of U251 cells showed an under- and overreaction of the cell phases which, compared with baseline results, was either significant (G2 phase) or close to being significant $(p<0.07)$, suggesting that these cells remained partially synchronised.

S-phase cells were further analysed by plotting the number of cells against DNA content (Fig. 4 shows a representative experiment). This sub-analysis of the Sphase fractions showed that LN229 and U87 accumulated in early S phase up to $16 \mathrm{~h}$ and U251 cells up to $24 \mathrm{~h}$ post FdUrd pre-treatment. Release of the early S-phase block was observed at $24 \mathrm{~h}$ for LN229 and U87 and at $48 \mathrm{~h}$ for U251 cells.

\section{${ }^{125}$ I-IdUrd DNA incorporation rate in the presence of 3 $\mu M$ unlabelled IdUrd}

In order to directly compare radio-IdUrd DNA incorporation and cell cycling, a comparison at identical IdUrd concentrations ( $3 \mu M$ unlabelled IdUrd) was performed on LN229 and U251 cells. In the FACS analysis, the use of 3 or $10 \mu M$ unlabelled IdUrd gave identical cell cycle

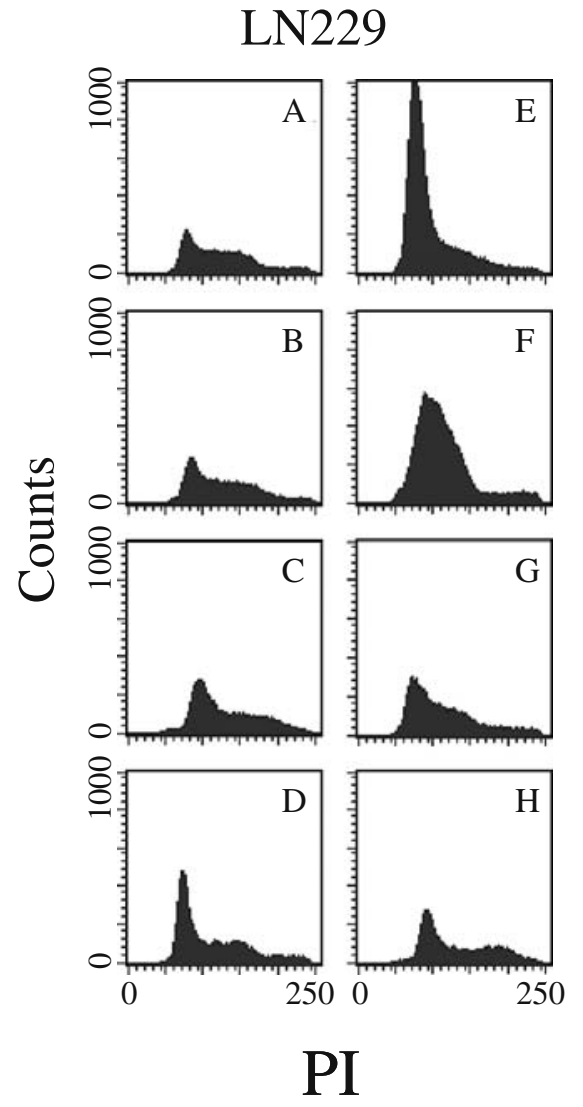

Fig. 4. Sub-analysis of S-phase cells according to interval after $1 \mathrm{~h}$ pre-treatment with $1 \mu M$ FdUrd. IdUrd immunofluorescence-stained S-phase cells have been further analysed by plotting cell counts against DNA content, revealed by PI staining. Analyses of a representative experiment for LN229 are shown. a Untreated control; b $0 \mathrm{~h}$ post $\mathrm{FdUrd}$; $3 \mathrm{~h}$ post FdUrd; d $6 \mathrm{~h}$ post FdUrd; e $16 \mathrm{~h}$ post FdUrd; f $24 \mathrm{~h}$ post FdUrd; $\mathbf{g} 48 \mathrm{~h}$ post FdUrd; $\mathbf{h} 72 \mathrm{~h}$ post FdUrd. Note that the block-release of cells occurs at $24 \mathrm{~h}$ in LN229 (f) 
distributions with notably similar S-phase rates after FdUrd pre-treatment (Table 1). ${ }^{125}$ I-IdUrd DNA incorporation measurements were therefore performed using incubation of pre-treated cells with ${ }^{125}$ I-IdUrd in the presence of $3 \mu M$ unlabelled IdUrd. The presence of the additional $3 \mu M$ unlabelled IdUrd partially decreased the radio-IdUrd DNA incorporation compared with experiments with radioIdUrd alone. In both cell lines, however, the optimal DNA incorporation increase was still observed at 16-24 h post FdUrd (Fig. 5). For both cell lines, LN229 and U251, the increase in uptake at 16 and $24 \mathrm{~h}$ was highly significant $(p<0.001)$ compared with untreated cells, and also compared with the incorporation immediately after FdUrd pre-treatment. These results therefore show that, under identical IdUrd concentrations, S-phase accumulation and the highest DNA incorporation rate of ${ }^{125}$ I-IdUrd remained time-correlated.

\section{Radiosensitivity after FdUrd pre-treatment}

These experiments were performed in order to test whether the S-phase arrested cells would exhibit any radioresistance. LN229 and U251 cells were pre-treated or not with $1 \mu M$ FdUrd for $1 \mathrm{~h}$. Cells were then irradiated with 2 or 6 Gy immediately after FdUrd exposure or after an interval of $20 \mathrm{~h}$, and survival evaluated by colony-forming assay. Results showed reproducibly that pre-treated cells

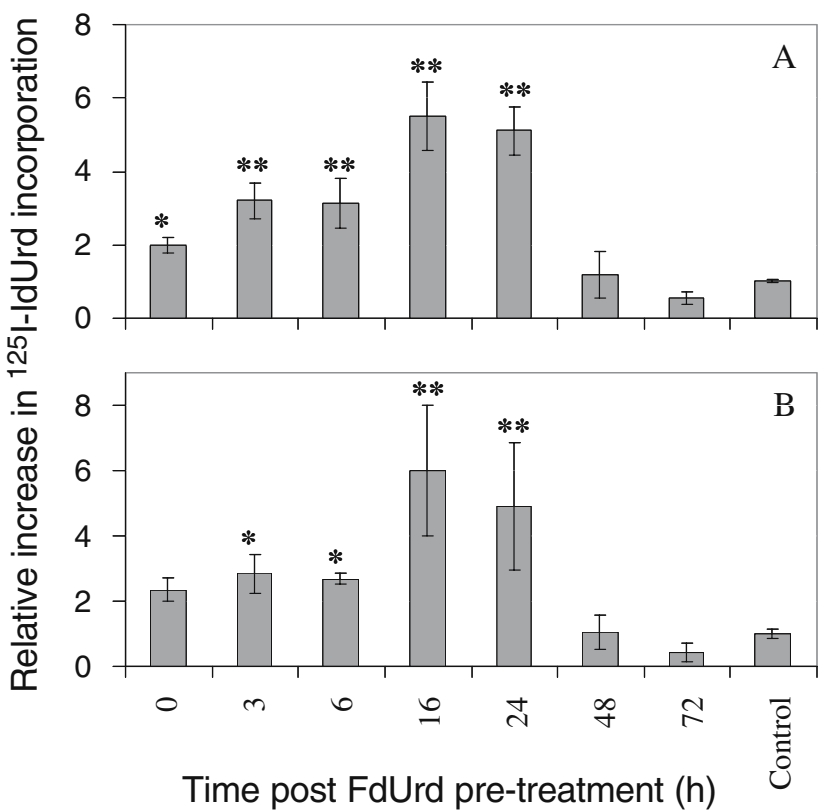

Fig. 5. Radio-IdUrd incorporation in the presence of $3 \mu M$ unlabelled IdUrd is shown for LN229 (a) and U251 (b) cells. The incorporation rate of ${ }^{125} \mathrm{I}$-IdUrd co-incubated for $2 \mathrm{~h}$ with $3 \mu \mathrm{M}$ unlabelled IdUrd is shown as relative increase in DNA incorporation of radio-IdUrd in FdUrd-pre-treated cells compared with un-pretreated control cells and normalised to the number of cells per well. Mean values $\pm 1 \mathrm{SD}$ of three independent experiments are given, each performed with three to four measurements per condition. ${ }^{*}$ and $* *$ denote results that were significantly $(p<0.05)$ or highly significantly $(p<0.001)$ different compared with untreated control cells

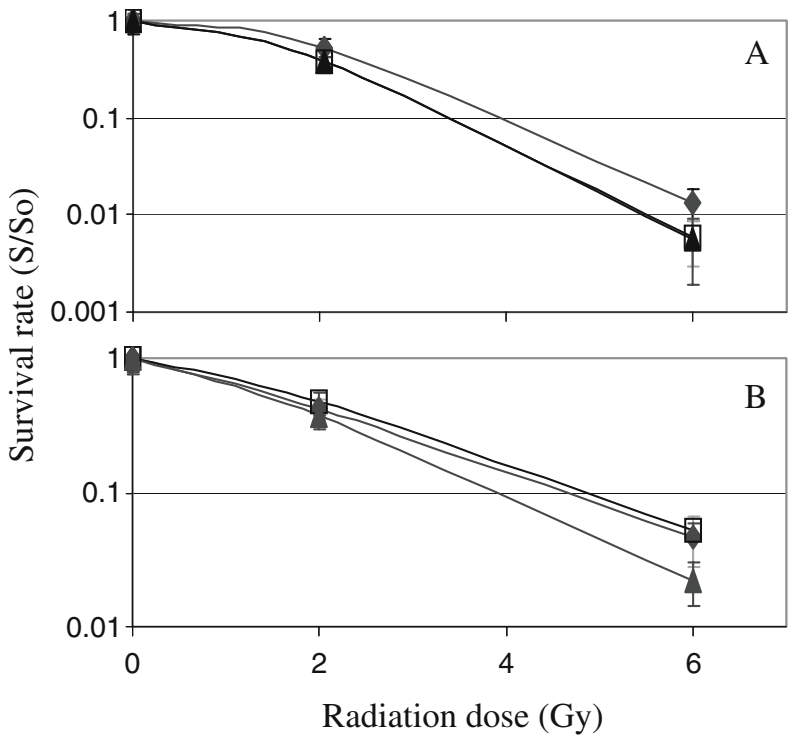

Fig. 6. Survival fractions of LN229 (a) and U251 (b) cells after external beam irradiation. Cells were irradiated after 0 - and 20-h intervals following pre-treatment or not with $1 \mu M$ FdUrd for $1 \mathrm{~h}$ : (४), un-pretreated controls; ( $\square$ ), $0 \mathrm{~h}$ post FdUrd; (ム), $20 \mathrm{~h}$ post FdUrd. Mean values \pm 1 SD of three independent experiments are shown; each experiment was performed with triplicate measurements per condition. Survival in the colony-forming assay has been normalised with unirradiated but otherwise identically treated control cells (S/So). Note that the increased cytotoxic effect following FdUrd pre-treatment was statistically significant $(p<0.05)$ in LN229 cells at both 0 and 20 h post irradiation with 2 and 6 Gy, while in U251 cells such a significant difference was observed only at $20 \mathrm{~h}$ and 6-Gy irradiation

were equally or more radiosensitive than un-pretreated cycling control cells (Fig. 6). An increased cytotoxic effect (statistically significant, $p<0.05$ ) after FdUrd pre-treatment was observed in LN229 cells at both 0 and $20 \mathrm{~h}$ post irradiation with 2 and $6 \mathrm{~Gy}$, while in U251 cells such a significant difference was only observed at $20 \mathrm{~h}$ post FdUrd and was limited to the 6-Gy irradiation. These results thus show the absence of any radio-resistance of the S-phaseenriched cell populations.

\section{Discussion}

A rational approach to radio-IdUrd Auger radiation therapy requires targeting of the highest possible number of cells and high DNA incorporation of radio-IdUrd. Previously, we have shown that short-term, non-toxic concentrations of FdUrd are able to induce high percentage DNA incorporation of radio-IdUrd in vitro and in vivo [6]. However, the number of targeted cells, namely the cells in S phase, remained low at the time of incubation/administration of radio-IdUrd immediately after FdUrd.

In this study, we therefore investigated cellular cycling and radio-IdUrd DNA incorporation after different intervals post FdUrd pre-treatment in three glioblastoma cell lines, aimed particularly at optimising S-phase targeting. We were able to show with highly reproducible FACS 
results that cell cycle evolution was remarkably similar in the three different glioblastoma cell lines. Baseline S-phase rates of untreated cells were between $18.5 \%$ and $28.7 \%$. Sphase cells then increased gradually up to $69.5 \%$ or more 16 and $24 \mathrm{~h}$ after $1 \mathrm{~h}$ pre-treatment with $1 \mu M$ FdUrd. This corresponds to an increase by a factor of between 2.5 and 4.1 over the baseline S-phase rates in the three cell lines. We also observed a similar S-phase rate accumulation after FdUrd pre-treatment in the ovarian cancer cell line SKOV3 (data not shown). These data confirm and extend a similar observation after FdUrd pre-treatment that was described for the human colon carcinoma cell line HT 29 [9]. HT 29 showed a particularly short doubling time of 22-24 h, and it was not obvious that cell lines with a longer cycling time would show similar S-phase accumulation. Furthermore, in the three glioblastoma cell lines explored, the difference in p53 expression [15], as observed frequently in recurrent tumour $[20,21]$, had no major impact on S-phase accumulation post FdUrd. In fact, the accumulation peaked to similar degrees in the three glioblastoma cell lines $16 \mathrm{~h}$ post FdUrd exposure.

The results reported here indicate that the observed Sphase increase corresponds to a synchronisation of cells rather than just an accumulation, since a grouped release from the block in early S phase was observed in the three glioblastoma lines after 16-24 hours. Furthermore, U251 cells remained partially synchronised as late as $72 \mathrm{~h}$ after FdUrd pre-treatment. The high S-phase rate in the three cell lines at 16 and $24 \mathrm{~h}$ post FdUrd is remarkable since the measured doubling times of these cells varied between 24 and $34 \mathrm{~h}$.

Cells accumulated in S -phase as late as 16 and $24 \mathrm{~h}$ after FdUrd pre-treatment continued to take up and incorporate IdUrd as soon as it became available. This was shown by their ability to incorporate unlabelled IdUrd in micromolar concentrations in the FACS analysis and also in nanomolar concentrations in the ${ }^{125}$ I-IdUrd DNA incorporation assay. Indeed, the radio-IdUrd DNA incorporation peaked at the time of maximal S-phase accumulation.

A further interesting observation was the high percentage of radio-IdUrd incorporated into tumour cells. In fact, the short availability of radio-IdUrd in vivo is a significant limitation for therapy. In these in vitro experiments, the uptake in absolute amount of radio-IdUrd rose from baseline incorporations of $2.4 \%-3.6 \%$ to between $16.4 \%$ and $50.7 \%$ at $24 \mathrm{~h}$ post FdUrd pre-treatment. Again, we observed a similar increase in uptake in SKOV3 ovarian cancer cells (results not shown). In vivo, without taking advantage of any S-phase increase after an interval post FdUrd, we observed that FdUrd pre-treatment enhanced the tumour uptake of radio-IdUrd in LN229 cells after intratumoural injections: tumour uptake reached $19.8 \%$ of the injected dose compared with only $4.1 \%$ in animals not pre-treated with FdUrd [12]. These data demonstrate that the short bio-availability of radio-IdUrd might be at least partially circumvented by the use of FdUrd or other dThd synthesis-blocking agents.
Evidence derived from radiobiology indicates that cell radiosensitivity is maximal in the $\mathrm{M}$, late $\mathrm{G} 1$ and early $\mathrm{S}$ phases and minimal in the early G1 and G2 phases [22]. However, arrested cells might respond differently to irradiation than cycling cells. It has been reported that fluoropyrimidine-mediated radiosensitisation is dependent on progression of cells into $\mathrm{S}$ phase under conditions of altered deoxynucleotide triphosphate pools [23]. The observation that the S-phase-enriched population $20 \mathrm{~h}$ post FdUrd treatment remained as, or slightly more, sensitive than untreated cycling cells therefore appears favourable. However, Auger radiation therapy with ${ }^{123} \mathrm{I}-$ or ${ }^{125}$ I-IdUrd will be active over one or several days, respectively. Efficacy of Auger radiation treatment, therefore, might be less dependent on cell cycling than external beam photon therapy, since Auger radiation induces a high percentage of double strand breaks that cannot be repaired efficiently.

These data might pave the way for treatment of high percentages of tumour cells in a single therapy cycle with Auger radiation pharmaceuticals such as ${ }^{123} \mathrm{I}-$ or ${ }^{125} \mathrm{I}-$ IdUrd. Furthermore, it has recently been shown that Auger radiation therapy can also produce a bystander effect [24]. This might allow treatment in a single cycle of more than just the S-phase cells targeted $16 \mathrm{~h}$ after the FdUrd pretreatment. However, the capacity to induce S-phase synchronisation in vivo remains to be demonstrated.

In conclusion, our results confirm and extend earlier observations in a colorectal cancer line to three human glioblastoma cell lines, with the observation of high percentage accumulation in early $\mathrm{S}$ phase delayed after FdUrd pre-treatment. We have further shown that these Sphase cells remained accessible to radio-IdUrd targeting at nanomolar up to micromolar concentrations and incorporated high percentages. Thus, highest radio-IdUrd DNA incorporation and S-phase accumulation were observed 16-24 $\mathrm{h}$ following FdUrd pre-treatment. The S-phaseenriched cell population was also shown to be as, or more, radiosensitive than un-pretreated cycling cells. The short FdUrd pre-treatment itself was non-toxic. Viewing these considerations in conjunction, it appears that the combination of FdUrd and radio-IdUrd could allow the rational design of a local Auger radiation treatment of cancer at optimised timing post FdUrd.

Acknowledgements. We thank Dr. Marek Kosinki for the preparation of high-purity ${ }^{125} \mathrm{I}$-IdUrd and Mrs. Frances Godson for reviewing the manuscript. This study was supported by a grant from the Swiss National Science Foundation (grant No 31-67112.01).

\section{References}

1. Commerford SL. Biological stability of 5-iodo-2'-deoxyuridine labelled with iodine-125 after its incorporation into the deoxyribonucleic acid of the mouse. Nature 1965;206:949-50

2. Blasberg RG, Roelcke U, Weinreich R, Beattie B, von Ammon $\mathrm{K}$, Yonekawa $\mathrm{Y}$, et al. Imaging brain tumor proliferative activity with $\left[{ }^{124}\right.$ I] iododeoxyuridine. Cancer Res 2000;60:624-35 
3. Klecker RW, Jr., Jenkins JF, Kinsella TJ, Fine RL, Strong JM, Collins JM. Clinical pharmacology of 5-iodo-2'-deoxyuridine and 5-iodouracil and endogenous pyrimidine modulation. Clin Pharmacol Ther 1985;38:45-51

4. Kassis AI, Guptill WE, Taube RA, Adelstein SJ. Radiotoxicity of 5-[ ${ }^{125}$ I] iodo-2'-deoxyuridine in mammalian cells following treatment with 5-fluoro-2'-deoxyuridine. J Nucl Biol Med 1991;35:167-73

5. Lawrence TS, Davis MA, McKeever PE, Maybaum J, Stetson PL, Normolle DP, et al. Fluorodeoxyuridine-mediated modulation of iododeoxyuridine incorporation and radiosensitization in human colon cancer cells in vitro and in vivo. Cancer Res 1991;51:3900-5

6. Dupertuis YM, Vazquez M, Mach JP, De Tribolet N, Pichard C, Slosman DO, et al. Fluorodeoxyuridine improves imaging of human glioblastoma xenografts with radiolabeled iododeoxyuridine. Cancer Res 2001;61:7971-7

7. Mester J, DeGoeij K, Sluyser M. Modulation of $\left[5^{-125} \mathrm{I}\right]$ iododeoxyuridine incorporation into tumour and normal tissue DNA by methotrexate and thymidylate synthase inhibitors. Eur J Cancer 1996;32A:1603-8

8. Armstrong RD, Diasio RB. Metabolism and biological activity of 5'-deoxy-5-fluorouridine, a novel fluoropyrimidine. Cancer Res 1980;40:3333-8

9. Miller EM, Kinsella TJ. Radiosensitization by fluorodeoxyuridine: effects of thymidylate synthase inhibition and cell synchronization. Cancer Res 1992;52:1687-94

10. Serlin O, Wolkoff JS, Amadeo JM, Keehn RJ. Use of 5fluorodeoxyuridine (FUDR) as an adjuvant to the surgical management of carcinoma of the stomach. Cancer 1969; 24: 223-8

11. Parsels LA, Parsels JD, Tai DC, Coughlin DJ, Maybaum J. 5Fluoro-2'-deoxyuridine-induced cdc25A accumulation correlates with premature mitotic entry and clonogenic death in human colon cancer cells. Cancer Res 2004;64:6588-94

12. Buchegger F, Adamer F, Schaffland AO, Kosinski M, Grannavel C, Dupertuis YM, et al. Highly efficient DNA incorporation of intratumourally injected $\left[{ }^{125} \mathrm{I}\right]$ iododeoxyuridine under thymidine synthesis blocking in human glioblastoma xenografts. Int J Cancer 2004;110:145-9

13. Schaffland AO, Delaloye AB, Kosinski M, Dupertuis YM, Buchegger F. The preparation of clinical grade 5-[ $\left.{ }^{123} \mathrm{I}\right]$ iodo-2'deoxyuridine and 5 -[ $\left.{ }^{125} \mathrm{I}\right]$ iodo-2'-deoxyuridine with high in vitro stability and the potential for early proliferation scintigraphy. Nucl Med Commun 2004;25:461-8
14. Foulon CF, Adelstein SJ, Kassis AI. Kit formulation for the preparation of radiolabeled iododeoxyuridine by demetallation. J Nucl Med 1996;37:1S-3S

15. Van Meir EG, Kikuchi T, Tada M, Li H, Diserens AC, Wojcik $\mathrm{BE}$, et al. Analysis of the $p 53$ gene and its expression in human glioblastoma cells. Cancer Res 1994;54:649-52

16. Parsels LA, Zellars RC, Loney TL, Parsels JD, Clarke MF, Merchant AK, et al. Prevention of fluorodeoxyuridine-induced cytotoxicity and DNA damage in HT29 colon carcinoma cells by conditional expression of wild-type $p 53$ phenotype. Mol Pharmacol 1997;52:600-5

17. Sinigaglia F, Talmadge KW. Inhibition of $\left[{ }^{3} \mathrm{H}\right]$ thymidine incorporation by Mycoplasma arginini-infected cells due to enzymatic cleavage of the nucleoside. Eur J Immunol 1985; 15:692-6

18. Wang L, Westberg J, Bolske G, Eriksson S. Novel deoxynucleoside-phosphorylating enzymes in mycoplasmas: evidence for efficient utilization of deoxynucleosides. Mol Microbiol 2001;42:1065-73

19. Xiao WH, Dupertuis YM, Mermillod B, Sun LQ, de Tribolet N, Buchegger F. Unlabelled iododeoxyuridine increases the cytotoxicity and incorporation of $\left[{ }^{125} 1\right]$-iododeoxyuridine in two human glioblastoma cell lines. Nucl Med Commun 2000; 21:947-53

20. Sidransky D, Mikkelsen T, Schwechheimer K, Rosenblum ML, Cavanee W, Vogelstein B. Clonal expansion of p 53 mutant cells is associated with brain tumour progression. Nature 1992; 355:846-7

21. Hayashi Y, Yamashita J, Yamaguchi K. Timing and role of $p 53$ gene mutation in the recurrence of glioma. Biochem Biophys Res Commun 1991;180:1145-50

22. Terasima T, Tolmach LJ. Variations in several responses of HeLa cells to $\mathrm{x}$-irradiation during the division cycle. Biophys $\mathrm{J}$ 1963;3:11-33

23. Hwang HS, Davis TW, Houghton JA, Kinsella TJ. Radiosensitivity of thymidylate synthase-deficient human tumor cells is affected by progression through the G1 restriction point into Sphase: implications for fluoropyrimidine radiosensitization. Cancer Res 2000;60:92-100

24. Xue LY, Butler NJ, Makrigiorgos GM, Adelstein SJ, Kassis AI. Bystander effect produced by radiolabeled tumor cells in vivo. Proc Natl Acad Sci U S A 2002;99:13765-70 